\title{
Contagem de células somáticas e produção de leite em vacas holandesas de alta produção(1)
}

\author{
Arlei Coldebella ${ }^{(2)}$, Paulo Fernando Machado(3) $^{(3)}$ Clarice Garcia Borges Demétrio ${ }^{(4)}$, \\ Paulo Justiniano Ribeiro Júnior( ${ }^{(5)}$, Carlos Humberto Corassin ${ }^{(3)}$, Paula Marques Meyer ${ }^{(6)}$ \\ e Laerte Dagher Cassoli ${ }^{(3)}$
}

\begin{abstract}
Resumo - A mastite bovina pode ser clínica, com sinais visíveis, e subclínica, diagnosticada pela contagem das células somáticas. As perdas econômicas causadas pela mastite subclínica devem ser quantificadas para atender à demanda nacional de produtos lácteos. O objetivo deste trabalho foi verificar se as perdas na produção de leite, pelo aumento do número de células somáticas, são proporcionais ou independentes do nível de produção. Foram utilizadas 7.756 observações, colhidas mensalmente de um único rebanho, de setembro de 2000 a junho de 2002. A curva de lactação foi modelada pela função gama incompleta, e os efeitos de ordem de lactação, época do parto, ocorrência de doenças no periparto e escore de condição corporal ao parto também foram considerados. A contagem de células somáticas foi incluída nesse modelo como fator multiplicativo, representando perdas relativas, e como fator aditivo, representando perdas absolutas. A escolha do melhor modelo foi baseada no critério de informação de Schwarz (BIC). As perdas são absolutas, evidentes a partir de 14.270 células $/ \mathrm{mL}$ e para cada aumento de uma unidade na escala do logaritmo natural a partir desse valor, estimam-se perdas de 184 e $869 \mathrm{~g} / \mathrm{dia}$ para vacas primíparas e multíparas, respectivamente.
\end{abstract}

Termos para indexação: bovino, lactação, mastite bovina.

\section{Somatic cells count and milk yield in high production Holstein cows}

\begin{abstract}
The goal of this paper was to evaluate if losses in milk yield due to increase in somatic cells count are proportional or independent of the level of production. A total of 7,756 observations, monthly collected from a single herd from September/2000 up to June/2002, were used. The lactation curve was modeled by the incomplete gamma function, considering the effects of lactation order, calving season, peripartum disorder incidence and body condition score at calving. Somatic cells count was added to the model as a multiplicative factor, representing relative losses, and as an additive factor, representing absolute losses. The best model was chosen based on the information criteria of Schwarz (BIC). The losses are absolute, becoming evident from 14,270 cells/mL, and they are 184 and $869 \mathrm{~g} /$ day for each increase of one unit in the natural logarithm scale, starting from that somatic cells count, for primiparous and multiparous cows, respectively.
\end{abstract}

Index terms: bovines, lactation, bovine mastitis.

(1) Aceito para publicação em 29 de agosto de 2003. Extraído da tese de doutorado apresentada pelo primeiro autor à Esalq, Piracicaba, SP. Financiada pela Fapesp.

(2) Embrapa-Centro Nacional de Pesquisa de Suínos e Aves, Caixa Postal 21, CEP 89700-000 Concórdia, SC E-mail: acoldebe@cnpsa.embrapa.br

(3) Esalq, Dep. de Zootecnia, Caixa Postal 9, CEP 13418-900 Piracicaba, SP.E-mail: pfmachad@esalq.usp.br, corassin@esalq.usp.br, ldcassol@esalq.usp.br

(4) Esalq, Dep.de Ciências Exatas. E-mail: clarice@esalq.usp.br

(5) Universidade Federal do Paraná, Dep. de Estatística, Setor de Ciências Exatas, Caixa Postal 19081, CEP 81531-990 Curitiba, PR. E-mail: paulo.ribeiro@est.ufpr.br

(6) IBGE, Unidade Estadual de São Paulo, Rua Urussuí, 93, 9o andar, CEP 04542-050 São Paulo, SP. E-mail: paulameyer@ibge.gov.br

\section{Introdução}

A mastite bovina é o fator que mais provoca perdas econômicas da cadeia produtiva do leite (Laranja \& Machado, 1994; Lescourret \& Coulon, 1994). Para suprir a demanda por produtos lácteos em quantidade e qualidade é necessário que as perdas na produção de leite causadas pela mastite sejam quantificadas, considerando as condições em que os nossos rebanhos são explorados.

A mastite pode ser clínica ou subclínica (Philpot \& Nickerson, 1991). A forma clínica caracteriza-se por apresentar sinais visíveis; enquanto a forma subclínica exige o emprego de outros métodos de 
diagnóstico, como a contagem de células somáticas (CCS), que é afetada, principalmente, pela infecção intramamária (Reneau, 1986; Harmon, 1994; Machado et al., 2000).

Em um rebanho típico dos Estados Unidos, a diminuição da produção de leite associada à mastite subclínica representa de $70 \%$ a $80 \%$ de todas as perdas econômicas advindas da mastite (Fetrow et al., 2000).

As estimativas dos efeitos da mastite no desempenho das vacas leiteiras mostraram grande variação (Schepers \& Dijkhuizen, 1991), o que pode ser atribuído às diferenças nas populações estudadas, aos indicadores de mastite e aos métodos estatísticos utilizados (Lescourret \& Coulon, 1994; Hortet et al., 1999).

Um modelo de perdas de produção causadas pela mastite deve considerar outras variáveis que influenciam a produção de leite, como o número de dias em lactação, representado pela curva de lactação (Wood, 1967; Rekaya et al., 2001), a ordem de lactação, ou idade da vaca (Friggens et al., 1999; Freitas et al., 2001; Rekaya et al., 2001), a época do parto (Durães et al., 2001), a ocorrência de doenças no periparto (Miettinen \& Setälä, 1993) e o escore de condição corporal ao parto (Ferguson et al., 1994; Broster \& Broster, 1998).

O objetivo deste trabalho foi verificar se as perdas na produção de leite, pelo aumento do número de células somáticas, são proporcionais ou independentes do nível de produção.

\section{Material e Métodos}

Foram utilizadas 7.756 observações, provenientes de 855 vacas da raça Holandesa, pertencentes ao rebanho da Fazenda Colorado, situada no Município de Araras, SP, região de clima subtropical, com temperatura média máxima de $35^{\circ} \mathrm{C}$ em dezembro, janeiro e fevereiro, e média mínima de $10^{\circ} \mathrm{C}$ em maio, junho e julho.

As observações foram realizadas de setembro de 2000 a junho de 2002, em vacas com no máximo cinco lactações, que variaram entre 11 e 305 dias. As vacas estavam confinadas em nove "free-stalls", dotados de ventiladores e aspersores acionados automaticamente quando a temperatura ambiente ultrapassava $23^{\circ} \mathrm{C}$. Eram alimentadas sete vezes ao dia, sendo a primeira refeição às $5 \mathrm{~h}$ e a última às 21h. A dieta das vacas foi total e única, com $15,9 \%$ de proteína bruta, $21,4 \%$ de fibra detergente ácido e $36,8 \%$ de fibra detergente neutro, segundo análise bromatológica, em que o volumoso perfez $44,2 \%$ da dieta, em matéria seca.

As fêmeas com mais de 150 dias em lactação e com escore de condição corporal maior ou igual a 2,75 , considerada condição corporal no mínimo regular, receberam injeções subcutâneas de somatotropina bovina (Boostin ${ }^{\circledR}$ ) a cada 14 dias.

As ordenhas foram realizadas três vezes ao dia, em sala do tipo Espinha de Peixe, 12×2, linha baixa, com sistema de coleta de dados, quanto à identificação do animal e produção de leite, informatizado (AFIMILK ${ }^{\circledR}$ - SAE AFIKIM).

As amostras de leite foram coletadas mensalmente, sempre na ordenha da manhã, transferidas diretamente do medidor para os frascos de coleta que continham Bronopol como conservante. A seguir, foram homogeneizadas por, no mínimo, $15 \mathrm{~s}$ e encaminhadas ao Laboratório de Fisiologia da Lactação, da Clínica do Leite, Departamento de Zootecnia da Escola Superior de Agricultura Luiz de Queiroz, Universidade de São Paulo, Piracicaba, SP, para determinação da CCS (em mil células/mL). A CCS foi estimada por citometria de fluxo pelo equipamento Somacount $300^{\circledR}$ (Bentley Instruments).

O banco de dados continha, ainda, a ocorrência de doenças no periparto e o escore de condição corporal ao parto (ECCP), com escala de 1 a 5 e variações de 0,25 unidades. As doenças consideradas foram aborto, retenção de placenta, quando os anexos fetais foram retidos por um período superior a 18 horas pós-parto, metrite primária, ocorrida até 20 dias pós-parto, e secundária, após caso de retenção de placenta, febre do leite, confirmada quando o animal respondeu imediatamente ao tratamento endovenoso com solução de gluconato de cálcio, cetose, considerada apenas após diagnóstico de cetose clínica nos primeiros 15 dias pós-parto e deslocamento de abomaso, caso confirmado após correção cirúrgica.

A descrição da curva de lactação das vacas baseou-se na função gama incompleta (Wood, 1967):

$y_{t}=\alpha t^{\beta} e^{-\gamma t}+\varepsilon$

em que: $y_{t}$ é a produção de leite no dia em lactação t; $\alpha$ é um parâmetro desconhecido que representa a produção de leite no início da lactação, responsável por abaixar ou elevar toda a curva de lactação, não alterando, contudo, seu formato geral; $\beta$ é um parâmetro desconhecido que está associado à fase de ascensão da produção de leite no início da lactação; $\gamma$ é um parâmetro desconhecido que está associado à fase de declínio da produção de leite após o pico, que ocorre quando $t=\beta / \gamma$; e $\varepsilon$ é o erro aleatório, suposto homocedástico, com variância $\sigma^{2}$, independente e normalmente distribuído. 
Por se tratar de modelo não-linear, porém totalmente linearizável, o modelo (1) foi ajustado utilizando-se a teoria de modelos lineares generalizados proposta por Nelder \& Wedderburn (1972), utilizando-se o procedimento GENMOD do SAS (SAS Institute, 1999).

Denotando-se a esperança matemática $E\left[Y_{t}\right]$ por $\mu_{t}$, pode-se linearizar sua expressão aplicando-se logaritmo natural:

$$
\eta_{\mathrm{t}}=\operatorname{Ln}\left(\mu_{\mathrm{t}}\right)=\operatorname{Ln}(\alpha)+\beta \operatorname{Ln}(\mathrm{t})-\gamma \mathrm{t}
$$

em que: $\eta_{\mathrm{t}}$ é o preditor linear, funcionalmente ligado à média $\mu_{\mathrm{t}}$ pela função logaritmo.

Desta maneira, o ajuste do modelo (1) foi efetuado supondo que a distribuição da produção de leite $\left(\mathrm{Y}_{\mathrm{t}}\right)$ é normal, com média $\mu_{\mathrm{t}}$ e variância $\sigma^{2}$, tendo o logaritmo como função de ligação, $\operatorname{Ln}(\mathrm{t})$ e t como variáveis explanatórias.

Considerou-se o modelo (1) como minimal, com três parâmetros, em relação ao número de parâmetros. Porém, como a curva de lactação pode ser influenciada por outros fatores para os quais dispunha-se de informação como ordem de lactação, época do parto, escore de condição corporal ao parto e ocorrência de doenças no periparto, foram ajustados diversos modelos contidos entre o modelo minimal e o modelo maximal, com 108 parâmetros:

$E\left[Y_{t i j k m}\right]=\mu_{t i j k m}=\alpha_{i j k m} t^{\beta_{i j k m}} e^{-\gamma_{i k m m} t}$

em que: $\left.\mathrm{E}_{\mathrm{tijkx}}\right]$ é a média da produção de leite no dia em lactação $\mathrm{t}(\mathrm{t}=11, \ldots, 305)$, na ordem de lactação $\mathrm{i}(\mathrm{i}=1,2 \mathrm{e}$ 3 ou superior), da época do parto $\mathrm{j}[\mathrm{j}=$ verão (meses de outubro a março) e inverno (meses de abril a setembro)], com a ocorrência de doenças no periparto $\mathrm{k}(\mathrm{k}=$ doente $\mathrm{e}$ sadia) e com ECCP $\mathrm{m}(\mathrm{m}=1$, para $\mathrm{ECCP} \leq 3 ; 2$, para $3<\mathrm{ECCP}<4$ e 3, para ECCP $\geq 4)$, representada por $\mu_{\mathrm{tijkm}} ; \mathrm{t}$ é o número de dias em lactação; $\alpha_{i j k m}, \beta_{i j k m}$ e $\gamma_{i j k m}$ são parâmetros desconhecidos e interpretados como em (1), contudo, variando com a ordem de lactação i, com a época do parto j, com a ocorrência de doença no periparto $\mathrm{k} e$ com o ECCP m.

A categorização do ECCP foi baseada no trabalho de Ferguson et al. (1994), que sugere um intervalo de 3,25 a 3,75 como ideal.

A escolha do melhor modelo foi baseada no critério de informação de Schwarz [BIC $=-2 \times \operatorname{Ln}$ (verossimilhança máx.) + no de parâmetros $\times$ Ln (n- de observações)], conforme SAS Institute (1999), sendo considerado o melhor aquele que apresentou o menor valor desse critério.

Após a escolha do melhor modelo para representar a curva de lactação dos animais, adicionou-se a ele um termo denotado por $\mathrm{x}$ com os valores de CCS, de modo que as perdas associadas ao aumento da CCS fossem relativas à produção (4), ou absolutas (5):

$\mathrm{E}\left[\mathrm{Y}_{\mathrm{tijkx}}\right]=\mu_{\mathrm{tijkx}}=\mathrm{M}(\phi) \mathrm{I}_{\mathrm{x}}{ }^{\delta}$;

$\mathrm{E}\left[\mathrm{Y}_{\mathrm{tijkx}}\right]=\mu_{\mathrm{tijkx}}=\mathrm{M}(\phi)+\delta \operatorname{Ln}\left(\mathrm{I}_{\mathrm{x}}\right)$

em que: $\left.\mathrm{EY}_{\mathrm{tijkn}}\right]$ é a média da produção de leite no dia em lactação t, na ordem de lactação i, na época do parto j, com ocorrência de doenças no periparto $\mathrm{k}$, com ECCP m e com CCS igual a $\mathrm{x}$, representada por $\mu_{\mathrm{tijkmx}} ; \mathrm{M}(\phi)$ é o modelo escolhido para representar a curva de lactação;

$\mathrm{I}_{\mathrm{x}}=\left\{\begin{array}{l}\mathrm{x}-\mathrm{x}_{0}+1, \text { se } \mathrm{x}>\mathrm{x}_{0} \\ 1, \text { caso contrário }\end{array}\right.$

em que: x é a CCS; $x_{0}$ é um parâmetro desconhecido que representa o valor da CCS a partir do qual começam a ocorrer perdas; e $\delta$ é um parâmetro desconhecido que, no modelo (4), representa o decréscimo proporcional da produção de leite em função do aumento da CCS e, no modelo (5), a quantidade de leite perdida por unidade logarítmica de aumento da contagem de células somáticas (CCS).

Com a inclusão da CCS, os modelos (4) e (5) passam a ser não-linearizáveis e o ajuste dos mesmos foi realizado pela utilização de métodos de ajuste não-linear, pelo procedimento NLMIXED do SAS (SAS Institute, 1999).

Como o valor do parâmetro $\delta$ pode variar com a ordem de lactação i, com a época do parto j, com a ocorrência de doença no periparto $\mathrm{k}$, com o ECCP $\mathrm{m}$ e com o estágio da lactação n ( $\mathrm{n}=$ início, 11 a 45 dias, meio, 46 a 179 dias e fim da lactação, 180 dias ou mais), foram ajustados 26 modelos contendo todas as possíveis combinações dessas variáveis ligadas a esse parâmetro, até terceira ordem, nos modelos de perdas relativas e absolutas, totalizando $52 \mathrm{mo}$ delos, entre os quais foi selecionado como o melhor o que apresentou o menor valor do critério de informação de Schwarz (BIC).

\section{Resultados e Discussão}

Entre os 90 modelos ajustados para descrever a curva de lactação, o modelo $y=\alpha_{i j} t^{\beta_{i j}} e^{-\gamma_{j} t}$, com 14 parâmetros, foi o que apresentou o menor BIC $(52.959,4)$ e, portanto, foi considerado o melhor modelo. O pior modelo foiy $=\alpha_{j \mathrm{~m}} \mathrm{t}^{\beta_{\mathrm{jm}}} \mathrm{e}^{-\gamma_{\mathrm{jm}} \mathrm{t}}$, com 18 parâmetros e BIC igual a 54.569,4.

Com relação ao melhor modelo, os parâmetros $\alpha$ e $\beta$ da curva de lactação variaram em função da ordem de lactação e da época do parto, ao passo que o parâmetro $\gamma$ mudou apenas em relação à época do 
parto. Isso evidencia que, além do número de dias em lactação, a produção de leite foi significativamente afetada pela ordem de lactação e pela época do parto, o que está de acordo com Friggens et al. (1999), Durães et al. (2001), Freitas et al. (2001) e com Rekaya et al. (2001), respectivamente.

O escore de condição corporal ao parto não afetou os parâmetros da curva de lactação, corroborando o estudo de Lago et al. (2001), que constataram que esse fator não influenciou significativamente a produção de leite até oito semanas pós-parto. Broster \& Broster (1998) afirmam que as evidências sobre o efeito do ECCP na produção de leite subsequiente são contraditórias, ou seja, alguns trabalhos mostraram benefício relacionado ao aumento do ECCP, mas outros não. Eles atestam que os resultados podem depender do plano nutricional pré-parto.

A ocorrência de doenças no periparto não afetou os parâmetros da curva de lactação, provavelmente porque os aspectos nutricionais e ambientais do rebanho estudado contrabalançaram as possíveis diferenças de produção.

Uma vez escolhido o modelo para descrever a curva de lactação, incorporou-se ao mesmo a contagem de células somáticas (CCS) e observou-se que essa variável afeta significativamente a produção de leite, pois em todos os modelos ocorreram reduções no valor do BIC quando comparados ao modeloy $=\alpha_{\mathrm{ij}} \mathrm{t}^{\beta_{\mathrm{ij}}} \mathrm{e}^{-\gamma_{\mathrm{j}}}$.

O modelo escolhido para CCS foi o de perdas absolutas: $y=\alpha_{\mathrm{ij}} \mathrm{t}^{\beta_{\mathrm{ij}}} \mathrm{e}^{-\gamma_{\mathrm{j}} \mathrm{t}}+\delta_{\mathrm{i}} \operatorname{Ln}\left(\mathrm{I}_{\mathrm{x}}\right)$, com $\delta$ variando apenas com a ordem de lactação, pois apresentou o menor BIC $(52.672,9)$.

Por causa da proximidade dos valores estimados de $\delta$ nas ordens de lactação dois e três ou superior, optou-se por testar se os $\delta$ poderiam ser considerados iguais nessas classes de ordem de lactação. $\mathrm{O}$ valor obtido de BIC igual a 52.664,2 no modelo reduzido com $\delta_{1}$, variando apenas entre vacas primíparas, na ordem de lactação um, e multíparas, na ordem de lactação dois ou superior, é menor do que o de BIC igual a 52.672,9 do modelo original, não sendo detectadas diferenças entre as perdas estimadas por $\delta_{1}$ nas vacas que estão na lactação de ordem dois ou superior.

As estimativas dos parâmetros $\alpha, \beta$ e $\gamma$ podem ser interpretadas como geradoras de curvas de lactação ideais em relação à CCS, nas condições de ordem de lactação e época do parto. Elas representam curvas de lactação nas quais não ocorrem perdas por causa da CCS, em situações em que o número de células somáticas é menor ou igual a 14.270 células/mL, evidenciado por $\mathrm{x}_{0}$ igual a 14,27 (Tabela 1$)$.

As estimativas do parâmetro $\alpha$ foram crescentes com o decorrer das ordens de lactação, indicando produções inferiores na primeira lactação, quando comparada às demais, e da segunda, quando comparada às posteriores. $\mathrm{O}$ comportamento das estimativas do parâmetro $\beta$ foi inverso ao do $\alpha$, mostrando a maior capacidade em manter a produção no decorrer da primeira lactação, já que o parâmetro $\gamma$, para mesma época de parto, não varia com a ordem de lactação. Resultados semelhantes foram obtidos por Friggens et al. (1999).

Em relação à época do parto, que indiretamente determina o estresse calórico, as vacas que mais sofreram com o período de temperaturas mais elevadas foram as de terceira lactação ou superior, o que é evidenciado pela maior diferença entre as estimativas do parâmetro $\alpha$ no inverno e no verão $(45,80$ e 41,09 , respectivamente), pois $\beta$ praticamente não mudou nas épocas do parto e $\gamma$ não variou com a ordem de lactação. As vacas paridas no inverno na maioria das vezes terminam a lactação no verão, período menos favorável à produção de leite - pelas temperaturas mais elevadas, principalmente. Isso determinou um maior valor de $\gamma$ comparado ao verão, o que foi contrabalançado pelos maiores valores de $\beta$ nas ordens de lactação um e dois, e não para três ou superior.

As estimativas do parâmetro $\delta$ foram de $-0,184$ e -0,869 em vacas primíparas e multíparas respectivamente, e representam as perdas de produção de leite $(\mathrm{kg} / \mathrm{dia})$ em função do aumento de uma unidade logarítmica da CCS, a partir de 14.270 células $/ \mathrm{mL}$.

Os resultados indicando diferentes perdas de produção de leite entre vacas primíparas e multíparas estão de acordo com Kirk (1984), Reneau (1986) e Hortet et al. (1999). Um dos poucos estudos cujos resultados não evidenciaram essa diferença é o de Gill et al. (1990). Contudo, as estimativas de perdas obtidas por esses autores foram muito semelhantes às do presente trabalho, no caso das vacas multíparas, com perdas de $1,45 \mathrm{~kg}$ de leite por dia com 25.000 células $/ \mathrm{mL}$ e 4,83 kg/dia com 200.000 células $/ \mathrm{mL}$. 
As maiores perdas nas vacas multíparas podem ser explicadas pelo agravamento na saúde do úbere desses animais, ocasionado pela maior possibilidade de infecção e dano permanente à glândula por infecções prévias (Bartlett et al., 1990), e também, porque vacas mais velhas tendem a ter infecções mais longas, causando danos mais extensos nos tecidos (Reneau, 1986).

Este trabalho é importante porque, além de mostrar que as perdas são absolutas, identifica matematicamente a partir de que ponto elas começam a ocorrer $\left(x_{0}=14,27\right)$. Em outros estudos semelhantes, esse resultado foi obtido apenas empiricamente. Por exemplo, Hortet et al. (1999) basearam-se em pesquisas de cultura bacteriológica negativa e de ausência de mastite clínica, para propor um ponto de corte de 50.000 células/mL, a partir do qual as perdas começariam a ocorrer. Kirk (1984) e Reneau (1986) consideraram que as perdas ocorreriam somente a partir de 100.000 células $/ \mathrm{mL}$.

Hortet et al. (1999) não encontraram diferenças significativas entre os estágios de lactação nas vacas primíparas, mas observaram efeitos significativos nas multíparas, com perdas crescentes no decorrer da lactação. Segundo esses autores, vacas na primeira lactação apresentaram uma redução de $0,30 \mathrm{~kg}$ de leite para 100.000 células $/ \mathrm{mL}$ e $0,61 \mathrm{~kg}$ para 200.000 células $/ \mathrm{mL}$, ao passo que vacas na segunda lactação, com CCS de 200.000 células/mL apresentaram redução na produção de leite de $0,63 \mathrm{~kg}$ aos 50 dias pós-parto, 0,92 kg aos 150 dias e 1,77 kg aos 250 dias pós-parto. Vacas de terceira lactação ou superior, com essa mesma CCS, apresentaram redução de $0,60 \mathrm{~kg}$, $1,09 \mathrm{~kg}$ e 1,85 kg, aos 50, 150 e 250 dias pós-parto, respectivamente.

Os resultados obtidos podem ser utilizados no cálculo das perdas de produção de leite para cada vaca em lactação, bastando multiplicar a estimativa correspondente do parâmetro $\delta$ de cada ordem de lactação pelo logaritmo natural de $\mathrm{I}_{\mathrm{x}}$, sendo $\mathrm{I}_{\mathrm{x}}=\left\{\mathrm{x}-\mathrm{x}_{0}+1\right.$, se $\mathrm{x}>\mathrm{x}_{0} ; 1$, caso contrário $\}$, $\mathrm{x}$ a CCS e $\mathrm{x}_{0}=14,27$. A partir do resultado de cada vaca, podem-se estimar as perdas médias em virtude do aumento da CCS, refletindo o impacto da mastite subclínica em cada ordem de lactação (no caso, vacas primíparas e multíparas) e em relação ao rebanho, como um todo.

Desse modo, as vacas primíparas do rebanho estudado deixaram de produzir, em média, $0,617 \mathrm{~kg}$ de leite/vaca/dia por causa do aumento da CCS, ao passo que nas multíparas o valor foi de $3,266 \mathrm{~kg} / \mathrm{vaca} / \mathrm{dia}$. Globalmente, o rebanho deixou de produzir 2,273 kg de leite/vaca/dia devido à elevação da CCS.

Tabela 1. Estimativas dos parâmetros do modelo escolhido e intervalos de confiança $(95 \%)^{(1)}$.

\begin{tabular}{|c|c|c|c|c|c|}
\hline Época do parto & $\alpha$ & $\beta$ & $\gamma\left(\times 10^{2}\right)$ & $\delta$ & $\mathrm{x}_{0}$ \\
\hline & \multicolumn{5}{|c|}{ Ordem de lactação 1} \\
\hline Verão & $15,75(13,56: 17,94)$ & $0,191(0,157: 0,225)$ & $0,109(0,085: 0,134)$ & $-0,184$ & 14,27 \\
\hline \multirow[t]{2}{*}{ Inverno } & $14,14(12,56: 15,71)$ & $0,230(0,203: 0,256)$ & $0,176(0,156: 0,195)$ & $(-0,312:-0,056)$ & $(12,03: 16,52)$ \\
\hline & \multicolumn{5}{|c|}{ Ordem de lactação 2} \\
\hline Verão & $38,46(33,89: 43,03)$ & $0,043(0,012: 0,073)$ & $0,109(0,085: 0,134)$ & $-0,869$ & 14,27 \\
\hline \multirow[t]{2}{*}{ Inverno } & $36,94(33,57: 40,31)$ & $0,076(0,052: 0,099)$ & $0,176(0,156: 0,195)$ & $(-0,968:-0,771)$ & $(12,03: 16,52)$ \\
\hline & \multicolumn{5}{|c|}{ Ordem de lactação 3 ou superior } \\
\hline Verão & $41,09(36,77: 45,41)$ & $0,036(0,009: 0,064)$ & $0,109(0,085: 0,134)$ & $-0,869$ & 14,27 \\
\hline Inverno & $45,80(42,14: 49,47)$ & $0,035(0,013: 0,056)$ & $0,176(0,156: 0,195)$ & $(-0,968:-0,771)$ & $(12,03: 16,52)$ \\
\hline
\end{tabular}

${ }^{(1)} \alpha$ representa a produção de leite no início da lactação; $\beta$ está associado à fase de ascensão da produção de leite no início da lactação; $\gamma$ está associado à fase de declínio da produção de leite após o pico; $\delta$ representa a quantidade de leite perdida por unidade logarítmica de aumento da contagem de células somáticas; $x_{0}$ representa o número de células somáticas a partir do qual iniciam as perdas na produção de leite. 


\section{Conclusões}

1. Os parâmetros $\alpha$ e $\beta$ do modelo usado para descrever a curva de lactação variam com a ordem de lactação e com a época do parto, e o parâmetro $\gamma$ depende apenas da época do parto.

2. As perdas de produção de leite causadas pelo aumento das células somáticas são independentes da produção do animal.

\section{Agradecimento}

À Fundação de Amparo a Pesquisa do Estado de São Paulo (Fapesp), pelo apoio financeiro.

\section{Referências}

BARTLETT, P. C.; MILLER, G. Y.; ANDERSON, C. R.; KIRK, J. H. Milk production and somatic cell count in Michigan dairy herds. Journal of Dairy Science, Champaign, v. 73, n. 10, p. 2794-2800, 1990.

BROSTER, W. H.; BROSTER, V. J. Body score of dairy cows. Journal of Dairy Research, London, v. 65, p. 155173, 1998.

DURÃES, M. C.; FREITAS, A. F.; VALENTE, J.; TEIXEIRA, N. M.; BARRA, R. B. Tendência genética para a produção de leite e de gordura em rebanhos da raça holandesa no Estado de Minas Gerais. Revista Brasileira de Zootecnia, Viçosa, MG, v. 30, n. 1, p. 66-70, 2001.

FERGUSON, J. D.; BYERS, D.; FERRY, J.; JOHNSON, P.; RUEGG, P.; WEAVER, L. Roundtable discussion: body condition of lactation cows. Agri-Practice, Santa Barbara, v. 15, n. 4 , p. 17-21, 1994.

FET ROW, J.; STEWART, S.; EICKER, S.; FARNSWORTH, R.; BEY, R. Mastitis: an economic consideration. In: ANNUAL MEETING OF THE NATIONAL MASTITIS COUNCIL, 39., 2000, Atlanta. Proceedings... Madison: National Mastitis Council, 2000. p. 3-47.

FREITAS, A. F.; DURÃES, M. C.; VALENTE, J.; TEIXEIRA, N. M.; MARTINEZ, M. L.; MAGALHÃES JUNIOR, M. N. Parâmetros genéticos para produções de leite e gordura nas três primeiras lactações de vacas holandesas. Revista Brasileira de Zootecnia, Viçosa, MG, v. 30, n. 3, p. 709-713, 2001.

FRIGGENS, N. C.; EMMANS, G. C.; VEERKAMP, R. F. On the use of simple ratios between lactation curve coefficients to describe parity effects on milk production.
Livestock Production Science, Amsterdam, v. 62, p. 113, 1999 .

GILL, R.; HOWARD, W. H.; LESLIE, K. E.; LISSEMORE, K. Economics of mastitis control. Journal of Dairy Science, Champaign, v. 73, n. 11, p. 3340-3348, 1990.

HARMON, R. J. Physiology of mastitis and factors affecting somatic cell counts. Journal of Dairy Science, Champaign, v. 77, n. 7, p. 2103-2112, 1994.

HORTET, P.; BEAUDEAU, F.; SEEGERS, H.; FOURICHON, C. Reduction in milk yield associated with somatic cell counts up to 600.000 cells $/ \mathrm{mL}$ in French Holsteins cows without clinical mastitis. Livestock Production Science, Amsterdam, v. 61, n. 1, p. 33-42, 1999.

KIRK, J. H. Programmable calculator program for linear somatic cell scores to estimate mastitis yield losses. Journal of Dairy Science, Champaign, v. 67, n. 2, p. 441443, 1984.

LAGO, E. P.; PIRES, A. V.; SUSIN, I.; FARIA, V. P.; LAGO, L. A. Efeito da condição corporal ao parto sobre alguns parâmetros do metabolismo energético, produção de leite e incidência de doenças no pós-parto de vacas leiteiras. Revista Brasileira de Zootecnia, Viçosa, MG, v. 30, n. 5 , p. $1544-1549,2001$

LARANJA, L. F.; MACHADO, P. F. Ocorrência de mastite bovina em fazendas produtoras de leite B no Estado de São Paulo. Scientia Agricola, Piracicaba, v. 51, n. 3, p. 578-585, 1994.

LESCOURRET, F.; COULON, J. B. Modeling the impact of mastitis on milk production by dairy cows. Journal of Dairy Science, Champaign, v. 77, n. 8, p. 2289-2301, 1994.

MACHADO, P. F.; PEREIRA, A. R.; SILVA, L. F. P.; SARRIÉS, G. A. Células somáticas no leite em rebanhos brasileiros. Scientia Agricola, Piracicaba, v. 57, n. 2, p. $359-361,2000$.

MIETTINEN, P. V. A.; SETÄLÄ, J. J. Relationships between subclinical ketosis, milk production and fertility in Finnish dairy cattle. Preventive Veterinary Medicine, Amsterdam, v. 17, p. 1-8, 1993.

NELDER, J. A.; WEDDERBURN, R. W. M. Generalized linear models. Journal of the Royal Statistical Society A, London, v. 135, n. 3, p. 370-384, 1972. 
PHILPOT, W. N.; NICKERSON, S. C. Mastitis: counter attack. Naperville: Babson Bros, 1991. 150 p.

REKAYA, R.; WEIGEL, K. A.; GIANOLA, D. Hierarchical nonlinear model for persistency of milk yield in the first three lactations of Holsteins. Livestock Production Science, Amsterdam, v. 68, p. 181-187, 2001.

RENEAU, J. K. Effective use of dairy herd improvement somatic cell counts in mastitis control. Journal of Dairy Science, Champaign, v. 69, n. 6, p. 1708-1720, 1986.
SAS INSTITUTE (Cary, Estados Unidos). SAS/STAT user's guide 8.0. Cary, 1999. CD-ROM.

SCHEPERS, J. A.; DIJKHUIZEN, A. A. The economics of mastitis and mastitis control in dairy cattle: a critical analysis of estimates published since 1970. Preventive Veterinary Medicine, Amsterdam, v. 10, p. 213-224, 1991.

WOOD, P. D. P. Algebraic model of the lactation curve in cattle. Nature, London, v. 216, p. 164-165, 1967. 